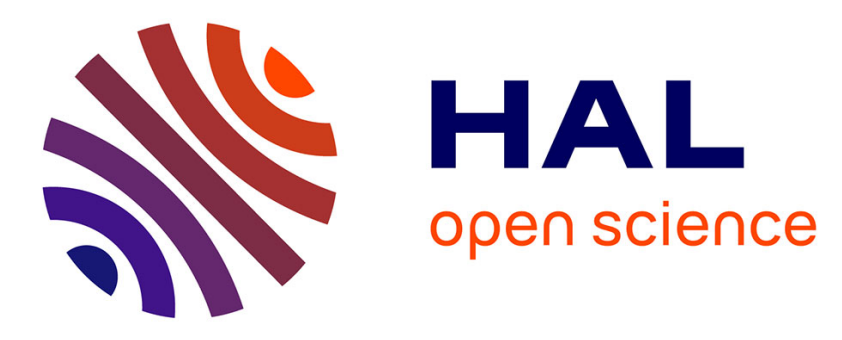

\title{
Hypoxic burden and heart-rate variability predict stroke incidence in sleep apnoea
}

\author{
Margaux Blanchard, Chloé Gervès-Pinquié, Mathieu Feuilloy, Marc Le \\ Vaillant, Wojciech Trzepizur, Nicole Meslier, François Goupil, Thierry \\ Pigeanne, Frédéric Balusson, Emmanuel Oger, et al.
}

\section{To cite this version:}

Margaux Blanchard, Chloé Gervès-Pinquié, Mathieu Feuilloy, Marc Le Vaillant, Wojciech Trzepizur, et al.. Hypoxic burden and heart-rate variability predict stroke incidence in sleep apnoea. European Respiratory Journal, 2021, 57 (3), pp.2004022. 10.1183/13993003.04022-2020 . hal-03040088

\section{HAL Id: hal-03040088 \\ https://hal.science/hal-03040088}

Submitted on 7 Jan 2021

HAL is a multi-disciplinary open access archive for the deposit and dissemination of scientific research documents, whether they are published or not. The documents may come from teaching and research institutions in France or abroad, or from public or private research centers.
L'archive ouverte pluridisciplinaire HAL, est destinée au dépôt et à la diffusion de documents scientifiques de niveau recherche, publiés ou non, émanant des établissements d'enseignement et de recherche français ou étrangers, des laboratoires publics ou privés. 
Article type: Research letter

Title: Hypoxic burden and heart-rate variability predict stroke incidence in sleep apnoea.

Cover title: Sleep apnoea, heart-rate variability, and stroke

Margaux Blanchard ${ }^{1,2}$, Chloé Gervès-Pinquié ${ }^{3}$, Mathieu Feuilloy ${ }^{1,2}$, Marc Le Vaillant ${ }^{3}$, Wojciech Trzepizur $^{4,5}$, Nicole Meslier ${ }^{4,5}$, François Goupil ${ }^{6}$, Thierry Pigeanne ${ }^{7}$, Frédéric Balusson ${ }^{8}$, Emmanuel Oger $^{8}$, AbdelKebir Sabil ${ }^{9}$, Jean-Marc Girault ${ }^{1,2}$, Frédéric Gagnadoux ${ }^{4,5}$, on behalf of the ERMES study group.

${ }^{1}$ ESEO, Angers, France

${ }^{2}$ LAUM, UMR CNRS 6613, Le Mans, France

${ }^{3}$ Pays de la Loire Respiratory Health Research Institute, Beaucouzé, France

${ }^{4}$ Department of Respiratory and Sleep Medicine, Angers University hospital, Angers, France

${ }^{5}$ INSERM Unit 1063, Angers, France

${ }^{6}$ Department of Respiratory Diseases, Le Mans General Hospital, Le Mans, France

${ }^{7}$ Respiratory Unit, Pôle santé des Olonnes, Olonne sur Mer, France

${ }^{8}$ Rennes University, Rennes University Hospital, EA 7449 [Pharmacoepidemiology and Health Services Research] REPERES, F 35043 Rennes

${ }^{9}$ Cloud Sleep Lab, Paris, France

Corresponding author: Frédéric Gagnadoux, Department of Respiratory and Sleep Medicine, Angers University hospital, 4 rue Larrey, 49100 Angers, France; phone: 33 241353695; fax: 33 241354974; email: frgagnadoux@chu-angers.fr 


\section{Manuscript word count: 1,374}

"take home" message: Indices of sleep apnoea-related hypoxic burden and heart rate variability derived from full-night polysomnography might be useful for identifying sleep apnoea patients at risk for stroke.

Keywords: Obstructive sleep apnoea; hypoxic burden, heart rate variability, stroke

Obstructive sleep apnoea (OSA) is increasingly recognized as a risk factor for stroke [1]. However, the incidence of stroke in patients investigated for OSA has been assessed in a limited number of studies reporting conflicting results on the association between the apnoea-hypopnea index (AHI) and stroke incidence [1-3]. As OSA is a very heterogeneous condition, the identification of subgroups of patients at high risk for stroke would be clinically desirable, in order to implement preventive actions [1]. Population-based studies have demonstrated that the sleep apnoea specific hypoxic burden (SASHB), an easily derived signal from polysomnography (PSG), predicts cardiovascular mortality and incident heart failure $[4,5]$. A recent study has demonstrated that night-time heart rate variability (HRV) might play an important role in the association between OSA and the cerebral small vessel disease, which is responsible for a substantial proportion of strokes [6]. Whether physiological markers of SASHB and HRV might be useful in clinical setting for identifying those patients with OSA at risk for stroke remains to be determined. Within a large multicentre clinic-based cohort of patients investigated for OSA, we hypothesized that PSG-derived indices of SASHB and HRV could predict stroke incidence.

The study was conducted on the Pays de la Loire Sleep Cohort, linked with data from the French administrative health care database (SNDS) (see ref [7] for details on the Pays de la Loire Sleep Cohort and the process linking it with the SNDS). We included stroke-free patients with available SNDS data investigated by PSG (CID102L8DTM, CIDELEC, Sainte-Gemmes-sur-Loire, France) for OSA between May 15, 2007 and December 31, 2017. Respiratory events were scored manually using 
recommended criteria [8]. As previously described, the SASHB was defined as the total area under the respiratory event-related desaturation curve [4]. Using standard recommendations [9], HRV was computed on 5 minute segments of continuous non-overlapping PSG-derived ECG without ectopy or artefact. Time domain HRV measurements included the standard deviation for the mean value of all normal-to-normal R-R intervals (SDNN) and the root mean square of successive differences in normal-to-normal R-R intervals (RMSSD). Frequency-domain measurements included the normalized low frequency (LF, from 0.04 to $0.15 \mathrm{~Hz}$ ) and high frequency power ( $\mathrm{HF}$, from 0.15 to $0.4 \mathrm{~Hz}$ ). The $\mathrm{LF}$ to $\mathrm{HF}$ ratio (LF/HF) estimated the sympathetic/parasympathetic tone.

The study endpoint was the first episode of stroke at any time between the PSG recording date and the end of December 2018. The first occurrence of stroke was identified from the national hospital discharge database (PMSI) and defined as the entry date of the first hospitalization with a discharge diagnosis G45, G46, 160-164, or 169 [10]. The accuracy of PMSI-based algorithm for stroke has been previously demonstrated with a positive predictive value at $90 \%$ [10]. As all physicians routinely contribute to PMSI data collection with annual quality control of coding, the accuracy increases with time [11].

Cox proportional hazard models were used to evaluate the association of stroke incidence with natural log transformed indices of OSA severity and HRV. Missing values were imputed using a multiple imputation method (MI procedure from SAS) [7]. Associations were considered statistically significant for a $p$ value $<0.05$. All statistical analyses were performed with SAS 9.4 software (SAS Institute, Cary, NC).

The study population consisted of 3,597 patients (median [interquartile range, IQR] age: 58 [48-67] years), predominantly male (63\%), obese or overweight (median [IQR] body-mass index [BMI] = 28 [25-32] $\mathrm{kg} / \mathrm{m}^{2}$ ), frequently presenting cardiovascular and metabolic comorbidities (hypertension, 28.6\%; diabetes, $10.4 \%$; cardiac diseases, $8.7 \%$ ), $85.4 \%$ of whom had mild-to-severe OSA (median [IQR] AHI = 20 [8-35] events/h). During follow-up, 1,159 patients were positive airway pressure (PAP) 
adherent (mean daily PAP use $\geq 4$ h). After a median follow-up of 5.9 [3.5-8.4] years, 83 patients had been diagnosed with a stroke including 70 ischemic ( 29 transient ischemic attack, TIA) and 13 haemorrhagic strokes (stroke incidence density rate $=3.9$ per 1,000 person-years). Cox proportional hazard models (Table 1) demonstrated an association between natural log transformed indices of OSA severity and stroke incidence (Model 1 ), which remained significant after adjusting for confounding risk factors (Model 2) for SASHB and the percentage of sleep time with oxygen saturation $<90 \%$ (T90) ( $p=0.02$ for both). Among natural log transformed indices of HRV, stroke incidence was negatively associated with LF and LF/HF ratio ( $p=0.01$ and 0.008 respectively) and positively associated with HF ( $p=0.01$ ) after adjusting for confounders (Model 2 ). The magnitude of the associations was unchanged after adjusting for PAP adherence (Model 3) and controlling for a competing risk of death (not shown).

When the analysis was restricted to 70 ischemic cerebrovascular events, stroke incidence remained significantly associated with natural log transformed SASHB (adjusted hazard ratio, HR [95\% confidence interval]: 1.30 [1.05-1.61]; $p=0.02$ ) and LF/HF ratio (adjusted HR: 0.66 [0.47-0.93]; $p=0.02$ ) in the fully adjusted model (Model 3). After exclusion of 29 TIA from the analysis, stroke incidence remained significantly associated with natural log transformed LF/HF ratio (adjusted HR: 0.60 [0.41-0.90]; $p=0.01$ ) but not with SASHB (adjusted HR: 1.17 [0.92-0.1.48]; $p=0.2$ ).

Adding interaction terms in the analyses showed no significant interaction of gender and PAP adherence in the relationship between natural log transformed PSG-derived indices and stroke incidence. However, stroke incidence was more strongly associated with SASHB and HF among nonobese subjects compared with those with obesity. The association of stroke incidence with SASHB and LF/HF was also stronger in patients aged $\geq 60$ years compared with those aged $<60$ years (all $p$ values for interactions $<0.05)$.

In a large multicentre, clinic-based cohort, we demonstrated an association of stroke incidence with PSG-derived indices of OSA-related hypoxaemia and HRV. Patients with higher SASHB and lower 
sympathetic/parasympathetic tone (LF/HF ratio) were at higher risk of stroke after adjusting for confounding risk factors and PAP adherence.

A strong association between untreated OSA and incident strokes ( $n=17$ events) have been previously reported in women [2]. Conversely, Kendzerska et al. [3] reported that stroke in OSA was not associated with $\mathrm{AHI}$. In the present study, we found no relationship between stroke incidence and common metrics of OSA severity excepted for T90 which characterizes not only OSA-related intermittent hypoxaemia, but also persistent hypoxaemia, such as that due to obesity hypoventilation or heart failure. Conversely, we demonstrated a dose-response relationship between stroke incidence and SASHB. Altogether, our findings and those from recent reports $[4,5]$ suggest that SASHB might predicts stroke and cardiovascular morbidity more consistently than AHI, ODI and T90.

Previous studies have demonstrated a relationship between HRV and stroke [12]. In subjects with OSA, the sympathetic activation that occurs toward the end of obstructive events is accompanied by vagally mediated bradycardia due to activation of the diving reflex [13]. In older men with OSA, sleep-related reduced sympathetic/parasympathetic tone is associated with a higher risk of atrial fibrillation [14], which has been consistently associated with stroke risk. In the present study, a oneunit increase in natural log transformed LF/HF ratio was associated with a $44 \%$ decrease in stroke risk, suggesting a contribution of low sympathetic/parasympathetic tone to stroke occurrence.

The strength of the current study includes a multicentre design, the adjustment for multiple stroke risk factors, and the assessment of different OSA severity and HRV indices. Our study also has some limitations. Its observational design does not allow any conclusions to be drawn regarding the causal pathway of the associations. Potential unmeasured confounding factors cannot be excluded. The use of a composite outcome combining different types of cerebrovascular events is also a potential limitation. We acknowledge that our study did not have sufficient statistical power to examine the association of OSA severity and HRV indices with the different stroke subtypes. All patients were 
investigated by in-laboratory overnight PSG using the same device. Further studies are required to evaluate the reproducibility of PSG-derived indices of SASHB and HRV. Furthermore, the high prevalence of OSA has led to an increasing use of simplified home sleep apnoea testing, with no ECG signal [15]. Whether oximetry-derived indices of pulse rate variability could provide an accurate estimation of HRV and predict stroke incidence should be also evaluated.

In conclusion, within a large clinic-based cohort of patients with suspected OSA, we demonstrated an association of SASHB and nigh-time sympathetic/parasympathetic tone with stroke risk. PSGderived indices of hypoxic burden and heart rate variability may provide an opportunity to allow for stroke risk stratification in patients with OSA. 


\section{Acknowledgments}

We thank the French National Health Insurance for giving us access to the French administrative health care database.

We thank the ERMES study group: Centre Hospitalier Universitaire, Angers: Christine Person, Pascaline Priou; Centre Hospitalier, Le Mans: Olivier Molinier, Audrey Paris.

We thank Christelle Gosselin and Jean-Louis Racineux from the Institut de Recherche en Santé Respiratoire des Pays de le Loire

We thank Julien Godey, Laetitia Moreno and Marion Vincent, sleep technicians in the Department of Respiratory and Sleep Medicine of Angers University Hospital

\section{Sources of Funding}

This study was supported by a grant from the Pays de la Loire Respiratory Health Research Institute (IRSR), Beaucouzé, France. 


\section{References}

1. Bassetti CLA, Randerath W, Vignatelli L, Ferini-Strambi L, Brill A-K, Bonsignore MR, Grote L, Jennum P, Leys D, Minnerup J, Nobili L, Tonia T, Morgan R, Kerry J, Riha R, McNicholas WT, Papavasileiou V. EAN/ERS/ESO/ESRS statement on the impact of sleep disorders on risk and outcome of stroke. Eur. Respir. J. 2020; 55.

2. Campos-Rodriguez F, Martinez-Garcia MA, Reyes-Nuñez N, Caballero-Martinez I, CatalanSerra P, Almeida-Gonzalez CV. Role of sleep apnea and continuous positive airway pressure therapy in the incidence of stroke or coronary heart disease in women. Am. J. Respir. Crit. Care Med. 2014; 189: $1544-1550$.

3. Kendzerska T, Gershon AS, Hawker G, Leung RS, Tomlinson G. Obstructive Sleep Apnea and Risk of Cardiovascular Events and All-Cause Mortality: A Decade-Long Historical Cohort Study. Patel A, editor. PLoS Med. 2014; 11: e1001599.

4. Azarbarzin A, Sands SA, Stone KL, Taranto-Montemurro L, Messineo L, Terrill PI, Ancoli-Israel S, Ensrud K, Purcell S, White DP, Redline S, Wellman A. The hypoxic burden of sleep apnoea predicts cardiovascular disease-related mortality: the Osteoporotic Fractures in Men Study and the Sleep Heart Health Study. Eur. Heart J. 2019; 40: 1149-1157.

5. Azarbarzin A, Sands SA, Taranto-Montemurro L, Vena D, Sofer T, Kim S-W, Stone KL, White DP, Wellman A, Redline S. The Sleep Apnea-Specific Hypoxic Burden Predicts Incident Heart Failure. Chest 2020; .

6. Del Brutto OH, Mera RM, Costa AF, Castillo PR. Effect of Heart Rate Variability on the Association Between the Apnea-Hypopnea Index and Cerebral Small Vessel Disease. Stroke 2019; 50: $2486-2491$.

7. Justeau G, Gervès-Pinquié $C$, Le Vaillant $M$, Trzepizur W, Meslier N, Goupil F, Pigeanne T, 
Launois S, Leclair-Visonneau L, Masson P, Bizieux-Thaminy A, Humeau M-P, Gosselin C, Blanchard M, Urban T, Gagnadoux F, ERMES study group. Association between nocturnal hypoxemia and cancer incidence in patients investigated for obstructive sleep apnea. Data from a large multicenter French cohort. Chest 2020; .

8. Berry RB, Budhiraja R, Gottlieb DJ, Gozal D, Iber C, Kapur VK, Marcus CL, Mehra R, Parthasarathy S, Quan SF, Redline S, Strohl KP, Davidson Ward SL, Tangredi MM, American Academy of Sleep Medicine. Rules for scoring respiratory events in sleep: update of the 2007 AASM Manual for the Scoring of Sleep and Associated Events. Deliberations of the Sleep Apnea Definitions Task Force of the American Academy of Sleep Medicine. J. Clin. Sleep Med. 2012; 8: 597-619.

9. Heart rate variability. Standards of measurement, physiological interpretation, and clinical use. Task Force of the European Society of Cardiology and the North American Society of Pacing and Electrophysiology. Eur. Heart J. 1996; 17: 354-381.

10. Giroud M, Hommel M, Benzenine E, Fauconnier J, Béjot Y, Quantin C, FRESCO Study. Positive Predictive Value of French Hospitalization Discharge Codes for Stroke and Transient Ischemic Attack. Eur. Neurol. 2015; 74: 92-99.

11. Aboa-Eboulé C, Mengue D, Benzenine E, Hommel M, Giroud M, Béjot $Y$, Quantin C. How accurate is the reporting of stroke in hospital discharge data? A pilot validation study using a population-based stroke registry as control. J. Neurol. 2013; 260: 605-613.

12. Lees T, Shad-Kaneez F, Simpson AM, Nassif NT, Lin Y, Lal S. Heart Rate Variability as a Biomarker for Predicting Stroke, Post-stroke Complications and Functionality. Biomark. Insights 2018; 13: 1177271918786931.

13. Linz D, McEvoy RD, Cowie MR, Somers VK, Nattel S, Lévy $P$, Kalman JM, Sanders P. Associations of Obstructive Sleep Apnea With Atrial Fibrillation and Continuous Positive Airway Pressure Treatment: A Review. JAMA Cardiol. 2018; 3: 532-540. 
14. Raman D, Kaffashi F, Lui L-Y, Sauer WH, Redline S, Stone P, Cawthon PM, Stone KL, Ensrud KE, Ancoli-Israel S, Loparo K, Mehra R. Polysomnographic Heart Rate Variability Indices and Atrial Ectopy Associated with Incident Atrial Fibrillation Risk in Older Community-dwelling Men. JACC Clin. Electrophysiol. 2017; 3: 451-460.

15. Collop NA, Anderson WM, Boehlecke B, Claman D, Goldberg R, Gottlieb DJ, Hudgel D, Sateia M, Schwab R, Portable Monitoring Task Force of the American Academy of Sleep Medicine. Clinical guidelines for the use of unattended portable monitors in the diagnosis of obstructive sleep apnea in adult patients. Portable Monitoring Task Force of the American Academy of Sleep Medicine. J. Clin. Sleep Med. 2007; 3: 737-747. 
Table 1: Cox proportional hazard models assessing the association of indices of obstructive sleep apnoea (OSA) severity and heart rate variability (HRV) with stroke incidence.

\begin{tabular}{|c|c|c|c|}
\hline & \multicolumn{3}{|c|}{ Hazard ratio [95\% confidence interval] } \\
\hline & Model 1 & Model 2 & Model 3 \\
\hline \multicolumn{4}{|l|}{ Indices of OSA severity } \\
\hline In AHI & $1.45[1.15-1.84]+$ & $1.18[0.93-1.50]$ & $1.20[0.93-1.55]$ \\
\hline In SASHB & $1.46[1.24-1.72] \ddagger$ & $1.25[1.04-1.51] *$ & $1.28[1.05-1.57] *$ \\
\hline In MAI & $1.44[1.01-2.05] *$ & $1.20[0.86-1.68]$ & $1.21[0.86-1.71]$ \\
\hline $\ln 3 \% O D I$ & $1.30[1.09-1.55]+$ & $1.13[0.95-1.33]$ & $1.13[0.95-1.35]$ \\
\hline $\ln$ T90 & $1.11[1.06-1.16] \ddagger$ & $1.06[1.01-1.12] *$ & $1.06[1.01-1.12] *$ \\
\hline \multicolumn{4}{|l|}{ Indices of HRV } \\
\hline In SDNN & 0.97 [0.59- 1.61] & 1.19 [0.73- 1.95] & $1.23[0.75-2.04]$ \\
\hline In RMSSD & $1.36[0.93-1.98]$ & 1.43 [0.99- 2.07] & $1.43[0.99-2.07]$ \\
\hline $\ln \mathrm{LF}$ & $0.36[0.21-0.64] \ddagger$ & $0.47[0.26-0.85] *$ & $0.47[0.26-0.86] *$ \\
\hline In HF & $3.35[1.48-7.61] \dagger$ & $2.78[1.25-6.17] *$ & $2.77[1.25-6.16] *$ \\
\hline In LF/HF ratio & $0.59[0.43-0.81] \dagger$ & $0.66[0.48-0.90]+$ & $0.66[0.48-0.90]+$ \\
\hline
\end{tabular}

Abbreviations: In, natural log transformed; $\mathrm{AHI}$, apnoea-hypopnea index; MAI, micro-arousal index; ODI, oxygen desaturation index; T90, percentage of sleep time with oxygen saturation $<90 \%$; SDNN, standard deviation for the mean of value of all normal-to-normal R-R intervals; RMSSD, root mean square of successive differences in normal-to-normal R-R intervals; LF, normalized low frequency power; HF, normalized high frequency power.

Model 1: unadjusted

Model 2: adjusted for age, gender, body mass index, alcohol intake, smoking status, diabetes, hypertension, history of cardiac disease and study site.

Model 3: Model $2+$ adjusted for positive airway pressure adherence

$* p<0.05 ;+p<0.01 ; \neq p<0.001$ 